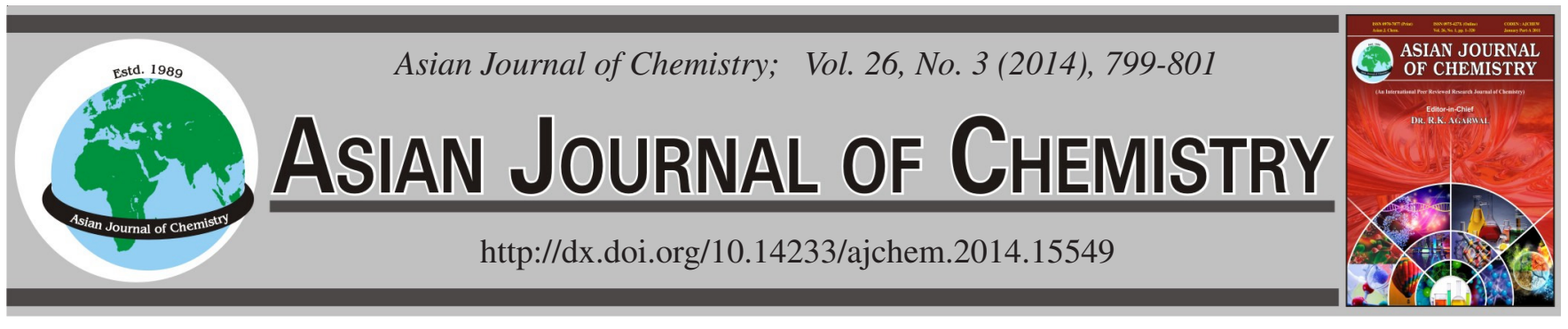

\title{
Synthesis and Characterization of Copper(II) Complexes with Salen-Type Bisoxime Chelating Ligand
}

\author{
Yin-Xia Sun ${ }^{*}$, Xin-Ran Li, Rui-E Lu and Wei-ShEng Meng
}

School of Chemical and Biological Engineering, Lanzhou Jiaotong University, Lanzhou 730070, P.R. China

*Corresponding author: E-mail: sun_yinxia@163.com

Two Cu(II) complexes 1 and $\mathbf{2}$ have been synthesized by the reaction of copper(II) picrate tetrahydrate and copper(II) perchlorate hexahydrate with a Salen-type bisoxime chelating ligand $\left(\mathrm{H}_{2} \mathrm{~L}=6,6^{\prime}\right.$-dimethoxy-2,2'-[ethylenedioxybis(nitrilomethylidyne)]diphenol) and characterized by elemental analyses, IR spectra, UV-visible spectra, TG-DTA analyses and molar conductances. The Salen-type bisoxime is a good tetradentate $\mathrm{N}_{2} \mathrm{O}_{2}$-donating ligand and the likely formula of the $\mathrm{Cu}$ (II) complexes may be suggested as $\mathrm{CuL} \cdot(\mathrm{HPic})_{2}(\mathbf{1})$ and $\mathrm{CuL} \cdot 2 \mathrm{H}_{2} \mathrm{O}$ (2).

Keywords: Cu(II) complex, Bisoxime ligand, Synthesis.

\section{INTRODUCTION}

Oxime-type compounds have long been used as chelating ligands in the synthesis of transition metal complexes due to their ease of preparation and structural variety. These compounds can accommodate one, two or more metal centers and form homo- and heteronuclear metal complexes with interesting properties ${ }^{1-4}$, such as excellent catalytic activity for epoxidation and aziridination ${ }^{5}$. In addition, they are also used as models for reaction centers in metalloenzymes ${ }^{6}$, non-linear optical materials ${ }^{7}$ and molecular recognition and biological activity $^{8}$. Herein, a new Salen-type bisoxime chelating ligand $\left(\mathrm{H}_{2} \mathrm{~L}=6,6\right.$ '-dimethoxy-2,2'-[ethylenedioxybis(nitrilomethyli dyne)]diphenol) and its $\mathrm{Cu}(\mathrm{II})$ complexes $\mathbf{1}$ and $\mathbf{2}$ have been synthesized and structurally characterized.

\section{EXPERIMENTAL}

3-Methoxy-2-hydroxybenzaldehyde ( $\geq 98 \%$ ) was purchased from Alfa Aesar and used without further purification. 1,2-Bis(aminooxy)ethane was synthesized according to an analogous method reported earlier ${ }^{4}$. The other reagents and solvents were analytical grade reagents from Tianjin Chemical Reagent Factory and were used without further purification. Elemental analysis for $\mathrm{Cu}$ was detected by an IRIS ER/S.WP$1 \mathrm{ICP}$ atomic emission spectrometer. C, $\mathrm{H}$ and $\mathrm{N}$ analyses were carried out with a GmbH VariuoEL V3.00 automatic elemental analyzer. FT-IR spectra were recorded on a VERTEX70 FT-IR spectrophotometer, with samples prepared as $\mathrm{KBr}(400-4000$ $\mathrm{cm}^{-1}$ ). UV-visible absorption spectra were recorded on a Shimadzu UV-2550 spectrometer. TG-DTA analyses were carried out at a heating rate of $5^{\circ} \mathrm{C} / \mathrm{min}$ on a ZRY-1P thermoanalyzer. Molar conductance value measurement was carried out on a model DDS-11D type conductivity bridge using $1.0 \times 10^{-3} \mathrm{~mol} \mathrm{dm}^{-3}$ solution in DMF at $25^{\circ} \mathrm{C}$.

Synthesis of ligand $\left(\mathbf{H}_{2} \mathbf{L}\right)$ : The ligand $\mathrm{H}_{2} \mathrm{~L}$ was synthesized with a slightly modified method reported literature ${ }^{4}$. Reaction of 1,2-bis(aminooxy)ethane (133.7 mg, $1.45 \mathrm{mmol}$ ) with 2 equiv. of 3-methoxy-2-hydroxybenzaldehyde ( $456 \mathrm{mg}$, $3.00 \mathrm{mmol})$ in ethanol $(10 \mathrm{~mL})$ at $55^{\circ} \mathrm{C}$ for $6 \mathrm{~h}$. After cooling to room temperature, the resulting solid was filtered and washed with ethanol and ethanol/hexane (1:4), respectively. The product was dried in vacuo and obtained $483.7 \mathrm{mg}$ of colorless microcrystal. m.p. $120-121^{\circ} \mathrm{C}$.

Synthesis of $\mathbf{C u}($ II) complex 1: A solution of copper(II) picrate tetrahydrate $(59.3 \mathrm{mg}, 0.10 \mathrm{mmol})$ in ethanol $(3 \mathrm{~mL})$ was added dropwise to a solution of $\mathrm{H}_{2} \mathrm{~L}(36.2 \mathrm{mg}, 0.10 \mathrm{mmol})$ in ethanol $(3 \mathrm{~mL})$ at room temperature. A green solution was obtained and stirred vigorously and refluxed for $3 \mathrm{~h}$. The resulting solid was filtered off, washed with ethanol/ether (1:4) and ether, respectively. The product was dried in vacuo and obtained $47.8 \mathrm{mg}$ of pale-green solid.

Synthesis of $\mathbf{C u}(\mathrm{II})$ complex 2: To an ethanol solution (5 mL) of $\mathrm{H}_{2} \mathrm{~L}(35.9 \mathrm{mg}, 0.10 \mathrm{mmol})$ was added an ethanol solution $(5 \mathrm{~mL})$ of copper(II) perchlorate hexahydrate (37.1 $\mathrm{mg}, 0.10 \mathrm{mmol}$ ). After the mixture solution had been stirred at $55^{\circ} \mathrm{C}$ for $4 \mathrm{~h}$, the formed precipitate was separated by filtration and washed successively with ethanol and ether, respectively. The product was dried under reduced pressure to obtain $25.5 \mathrm{mg}$ of pale-green solid. 
TABLE-1

COLOUR, YIELDS AND ANALYTICAL DATA OF $\mathrm{H}_{2}$ L AND ITS COPPER(II) COMPLEXES

\begin{tabular}{|c|c|c|c|c|c|c|c|c|}
\hline \multirow{2}{*}{ Comp. } & \multirow{2}{*}{ m.f. (m.w.) } & \multirow{2}{*}{ Colour } & \multirow{2}{*}{ Yield (\%) } & \multicolumn{4}{|c|}{ Found (calcd.) (\%) } & \multirow{2}{*}{$\begin{array}{l}\text { Molar conductance } \\
\left(\mathrm{S} \mathrm{cm}^{2} \mathrm{~mol}^{-1}\right)\end{array}$} \\
\hline & & & & $\mathrm{C}$ & $\mathrm{H}$ & $\mathrm{N}$ & $\mathrm{Cu}$ & \\
\hline $\mathrm{H}_{2} \mathrm{~L}$ & $\begin{array}{c}\mathrm{C}_{18} \mathrm{H}_{20} \mathrm{~N}_{2} \mathrm{O}_{6} \\
(360.4)\end{array}$ & Colorless & 83.6 & $\begin{array}{c}59.97 \\
(59.99)\end{array}$ & $\begin{array}{c}5.87 \\
(5.59)\end{array}$ & $\begin{array}{c}7.61 \\
(7.77)\end{array}$ & - & - \\
\hline 1 & $\begin{array}{c}\mathrm{C}_{30} \mathrm{H}_{24} \mathrm{~N}_{8} \mathrm{O}_{20} \mathrm{Cu} \\
(880.1)\end{array}$ & Pale-green & 54.3 & $\begin{array}{c}40.89 \\
(40.94)\end{array}$ & $\begin{array}{c}3.11 \\
(2.75)\end{array}$ & $\begin{array}{c}12.58 \\
(12.73)\end{array}$ & $\begin{array}{l}7.15 \\
(7.22)\end{array}$ & 2.78 \\
\hline 2 & $\begin{array}{c}\mathrm{C}_{18} \mathrm{H}_{22} \mathrm{~N}_{2} \mathrm{O}_{8} \mathrm{Cu} \\
(457.9) \\
\end{array}$ & Pale-green & 55.7 & $\begin{array}{c}47.38 \\
(47.21) \\
\end{array}$ & $\begin{array}{c}4.66 \\
(4.84) \\
\end{array}$ & $\begin{array}{c}6.08 \\
(6.12) \\
\end{array}$ & $\begin{array}{c}13.69 \\
(13.88)\end{array}$ & 1.53 \\
\hline
\end{tabular}

\section{RESULTS AND DISCUSSION}

Composition of $\mathrm{Cu}(\mathrm{II})$ complexes: The analytical results of $\mathrm{Cu}$ (II) complexes $\mathbf{1}$ and $\mathbf{2}$ are given in Table-1. Their compositions agree with the formula $\mathrm{CuL} \cdot(\mathrm{HPic})_{2}$ for complex $\mathbf{1}$ and $\mathrm{CuL} \cdot 2 \mathrm{H}_{2} \mathrm{O}$ for complex 2 . The molar conductance values of complexes $\mathbf{1}$ and $\mathbf{2}$ in $1.0 \times 10^{-3} \mathrm{~mol} \mathrm{dm}^{-3} \mathrm{DMF}$ solutions are 2.78 and $1.52 \mathrm{~S} \mathrm{~cm}^{2} \mathrm{~mol}^{-1}$ at $21{ }^{\circ} \mathrm{C}$, respectively, indicating that both are non-electrolytes. This implies that all of the picrate groups in complex $\mathbf{1}$ are present in the coordination sphere maybe through the hydrogen-bonding interactions in solution or solid state.

IR spectra of $\mathrm{H}_{2} \mathrm{~L}$ and $\mathrm{Cu}(\mathrm{II})$ complexes: The most important FT-IR spectra data for $\mathrm{H}_{2} \mathrm{~L}$ and its corresponding $\mathrm{Cu}(\mathrm{II})$ complexes are given in Table-2. The characteristic $\mathrm{C}=\mathrm{N}$ stretching band of the free ligand $\mathrm{H}_{2} \mathrm{~L}$ appears at $1605 \mathrm{~cm}^{-1}$, while the $\mathrm{C}=\mathrm{N}$ bands of $\mathrm{Cu}$ (II) complexes $\mathbf{1}$ and $\mathbf{2}$ are observed at 1608 and $1607 \mathrm{~cm}^{-1}$, respectively. The Ar-O stretching bands occur at $1262 \mathrm{~cm}^{-1}$ for $\mathrm{H}_{2} \mathrm{~L}$, whereas those at $1256 \mathrm{~cm}^{-1}$ and $1255 \mathrm{~cm}^{-1}$ for complexes $\mathbf{1}$ and $\mathbf{2}$, respectively. This shifting of $\mathrm{C}=\mathrm{N}$ and $\mathrm{Ar}-\mathrm{O}$ stretching frequency indicate that the $\mathrm{Cu}-\mathrm{N}$ and $\mathrm{Cu}-\mathrm{O}$ bonds are formed between the $\mathrm{Cu}(\mathrm{II})$ ions and the oxime $\mathrm{N}$ atoms and the phenolic oxygen atoms of the ligand $\mathrm{L}^{2-}$ unit ${ }^{4}$. The $\mathrm{O}-\mathrm{H}$ stretching band of the free ligand $\mathrm{H}_{2} \mathrm{~L}$ appears at $3435 \mathrm{~cm}^{-1}$, which disappears in complexes $\mathbf{1}$ and $\mathbf{2}$, indicating the oxygen atoms in the phenolic alcohol groups have been completely deprotoned and coordinated to $\mathrm{Cu}$ (II) ions. In addition, the $\mathrm{OH}$ out-of-plane bending vibration of the free picric acid at $1150 \mathrm{~cm}^{-1}$ appears in the spectra of complex 1, indicating that the $\mathrm{H}$-atom of the $\mathrm{OH}$ group existed in complex $\mathbf{1}^{9}$. Free picric acid has $\mathrm{v}_{\mathrm{as}}\left(-\mathrm{NO}_{2}\right)$ and $\mathrm{v}_{\mathrm{s}}\left(-\mathrm{NO}_{2}\right)$ at 1555 and $1342 \mathrm{~cm}^{-1}$, respectively, which split into two bands

\begin{tabular}{ccccc} 
& \multicolumn{4}{c}{ TABLE-2 } \\
\multicolumn{4}{c}{ KEY FT-IR BANDS FOR $\mathrm{H}_{2} \mathrm{~L}$} \\
AND ITS COPPER(II) COMPLEXES $\left(\mathrm{cm}^{-1}\right)$ \\
\hline Comp. & $v(\mathrm{C}=\mathrm{N})$ & $v(\mathrm{Ar}-\mathrm{O})$ & $v(\mathrm{O}-\mathrm{H})$ & $\begin{array}{c}v(\mathrm{C}=\mathrm{C}) \text { benzene } \\
\text { ring skeleton }\end{array}$ \\
\hline $\mathrm{H}_{2} \mathrm{~L}$ & 1605 & 1262 & 3435 & $1594,1512,1413$ \\
$\mathbf{1}$ & 1608 & 1256 & 3452 & $1596,1413,1415$ \\
$\mathbf{2}$ & 1607 & 1255 & 3446 & $1596,1413,1416$ \\
\hline
\end{tabular}

at $1576,1545 \mathrm{~cm}^{-1}$ and $1368,1337 \mathrm{~cm}^{-1}$. This indicates that some of the nitryl $\mathrm{O}$ atoms take part in coordination ${ }^{10}$. The broad bands at $3446 \mathrm{~cm}^{-1}$ are ascribed to the vibration of the water mole-cules in complex $2^{11}$.

UV-visible spectra of $\mathrm{H}_{2} \mathrm{~L}$ and $\mathrm{Cu}(\mathrm{II})$ complexes: The absorption spectra of $\mathrm{H}_{2} \mathrm{~L}$ and its corresponding $\mathrm{Cu}$ (II) complexes $\mathbf{1}$ and $\mathbf{2}$ (Table-3), in diluted DMF solution show that the spectra of complexes $\mathbf{1}$ and $\mathbf{2}$, are similar to each other, but are different from the spectrum of the ligand $\left(\mathrm{H}_{2} \mathrm{~L}\right)$. The UV-visible spectrum of the free ligand $\mathrm{H}_{2} \mathrm{~L}$ exhibits two absorption peaks at 272 and $318 \mathrm{~nm}$. The former absorption peak at $272 \mathrm{~nm}$ can be assigned to the $\pi-\pi^{*}$ transition of the benzene rings and the latter one at $318 \mathrm{~nm}$ can be attributed to the intra-ligand $\pi-\pi^{*}$ transition of the $\mathrm{C}=\mathrm{N}$ bonds ${ }^{12}$.

Compared with the absorption peak of the ligand, a corresponding absorption peak at 308 and $307 \mathrm{~nm}$ is observed in complexes $\mathbf{1}$ and $\mathbf{2}$, respectively, which is hypsochromically shifted by $10 \mathrm{~nm}$, indicating the coordination of $\mathrm{Cu}$ (II) ions with the ligand. Meanwhile, the absorption band at about 318 nm disappears from the UV-visible spectra of complexes $\mathbf{1}$ and $\mathbf{2}$, which indicates that the oxime nitrogen atom is involved in coordination to the metal atom ${ }^{13,14}$. In addition, the new bands observed at 360 and $375 \mathrm{~nm}$ for complexes $\mathbf{1}$ and $\mathbf{2}$ are assigned to the $n-\pi^{*}$ charge transfer transition from the filled $p \pi$ orbital of the bridging phenolic oxygen to the vacant $d$-orbital of the $\mathrm{Cu}$ (II) ions, which are characteristic of the transition metal complexes with $\mathrm{N}_{2} \mathrm{O}_{2}$ coordination spheres ${ }^{4,15}$.

Thermal properties: The thermal decomposition process of complexes $\mathbf{1}$ and $\mathbf{2}$ can be divided into three stages. The initial weight loss occurs in the range $152-185^{\circ} \mathrm{C}$ for complex 1 and $124-150{ }^{\circ} \mathrm{C}$ for complex 2 , corresponding to an endothermic peak and the TG curve shows that the weight loss corresponding to this temperature range is 25.9 and $12.1 \%$ that roughly coincides with the value of 26 and $11.8 \%$, respectively, calculated for the loss of two picric acid molecules of complex $\mathbf{1}$ and two water molecules of complex 2. On further heating, two exothermic peaks successively at 259 and $329^{\circ} \mathrm{C}$ for complex $\mathbf{1}$ (261 and $341{ }^{\circ} \mathrm{C}$ for complex 2 ) in the DTA curve and a continued weight loss occurs in the TG curve. Then, the second strong exothermic peak at $329^{\circ} \mathrm{C}$ for

TABLE-3

UV-VISIBLE SPECTRA DATA OF $\mathrm{H}_{2}$ L AND ITS COPPER(II) COMPLEXES

\begin{tabular}{cccccc}
\hline \multirow{2}{*}{ Comp } & \multirow{2}{*}{ Concentration $\left(\times 10^{-4} \mathrm{~mol} \mathrm{~L}^{-1}\right)$} & \multicolumn{3}{c}{ First band } & \multicolumn{2}{c}{ Second band } \\
\cline { 3 - 6 } & & $\lambda_{\max 1}(\mathrm{~nm})$ & $\varepsilon_{1}\left(\times 10^{4} \mathrm{~L} \mathrm{~mol}^{-1} \mathrm{~cm}^{-1}\right)$ & $\lambda_{\max 2}(\mathrm{~nm})$ & $\varepsilon_{2}\left(\times 10^{4} \mathrm{~L} \mathrm{~mol}^{-1} \mathrm{~cm}^{-1}\right)$ \\
\hline $\mathrm{H}_{2} \mathrm{~L}$ & 1.00 & 272 & 2.599 & 318 & 0.826 \\
$\mathbf{1}$ & 1.00 & 308 & 32.42 & 360 & 25.64 \\
$\mathbf{2}$ & 1.00 & 307 & 33.12 & 375 & 24.65 \\
\hline
\end{tabular}


complex 1 (at $341^{\circ} \mathrm{C}$ for complex 2) accompanied with further decomposition of the compound and the final solid product is likely to $\mathrm{CuO}$ with a residual value of $10.1 \%$ (theoretical value, $9.0 \%$ ) for complex 1 and 18.6 (theoretical value, $17.4 \%$ ) for complex 2 when the temperature is above $800{ }^{\circ} \mathrm{C}$.

\section{ACKNOWLEDGEMENTS}

The authors thank the Young Scholars Science Foundation of Lanzhou Jiaotong University (2011007) and the Fundamental Research Funds (212086) for the Gansu Province Universities for financial support of this work.

\section{REFERENCES}

1. S. Akine, T. Taniguchi and T. Nabeshima, Angew. Chem. Int. Ed., 41, 4670 (2002).

2. S. Akine, A. Akimoto, T. Shiga, H. Oshio and T. Nabeshima, Inorg. Chem., 47, 875 (2008)

3. S. Akine, T. Taniguchi and T. Nabeshima, Inorg. Chem., 43, 6142 (2004).

4. (a) W.K. Dong, J.G. Duan, L.Q. Chai, J.Y. Shi, G.L.Liu and H.L. Wu, J. Coord. Chem., 61, 1306 (2008); (b) W.K. Dong, J.Y. Shi, L. Xu, J.K. Zhong, J.G. Duan and Y.P. Zhang, Appl. Organomet. Chem., 22, 89 (2008); (c) W.K. Dong and J.G. Duan, J. Coord. Chem., 61, 781 (2008); (d) W.K. Dong, J.H. Feng, L. Wang, L. Xu, L. Zhao, X.Q. Yang and T.-Z. Yu, Transition Met. Chem., 32, 1101 (2007); (e) W.K. Dong, J.G. Duan and G.L. Liu, Transition Met. Chem., 32, 702 (2007); (f) W.K. Dong, J.Y. Shi, J.K. Zhong, Y.Q. Tian and J.G. Duan, Chin. J. Inorg. Chem., 24, 10 (2008); (g) W.K. Dong, J.Y. Shi, J.K. Zhong, Y.Q. Tian and J.G. Duan, Chin. J. Inorg. Chem., 24, 10 (2008); (h) W.K. Dong, C.E. Zhu, H.L.Wu, Y.J. Ding and T.Z. Yu, Synth. React. Inorg. Met.-Org. NanoMet. Chem., 37, 61 (2007); (i) W.K. Dong, X.N. He, H.B. Yan, Z.W. Lv, X. Chen, C.Y. Zhao and X.L. Tang, Polyhedron, 28, 1419 (2009); (j) W.K. Dong, J.G. Duan, Y.H. Guan, J.Y. Shi and C.Y. Zhao, Inorg. Chim. Acta, 362, 1129 (2009); (k) W.K. Dong, L. Li, C.F. Li, L. Xu and J.G. Duan, Spectrochim. Acta, 71, 650 (2008).

5. N.S. Venkataramanan, G. Kuppuraj and S. Rajagopal, Coord. Chem. Rev., 249, 1249 (2005).

6. M.F. Summers, L.G. Marzilli, N. Bresciani-Pahor and L. Randaccio, J. Am. Chem. Soc., 106, 4478 (1984).

7. P.G. Lacroix, Eur. J. Inorg. Chem., 339 (2001).

8. S.S. Sun, C.L. Stern, S.T. Nguyen and J.T. Hupp, J. Am. Chem. Soc., 126, 6314 (2004).

9. X.Q. Song, J.R. Zheng, W.S. Liu and Z.H. Ju, Spectrochim. Acta, 69, 49 (2008).

10. S.X. Liu, W.S. Liu, M.Y. Tan and K.B. Yu, J. Coord. Chem., 39, 105 (1996).

11. X.Q. Song, W.S. Liu, W. Dou, Y.W. Wang, J.R. Zheng and Z.P. Zang, Eur. J. Inorg. Chem., 1901 (2008).

12. T. Ghosh, B. Mondal, T. Ghosh, M. Sutradhar, G. Mukherjee and M.G.B. Drew, Inorg. Chim. Acta, 360, 1753 (2007).

13. H.E. Smith, Chem. Rev., 83, 359 (1983).

14. S. Akine, T. Taniguchi and T. Nabeshima, Chem. Lett., 30, 682 (2001).

15. L. Gomes, E. Pereira and B. de Castro, J. Chem. Soc. Dalton Trans., 1373 (2000). 